\title{
The 1973 National Economic Plan: Slowing The Boom
}

\author{
by KEITH M. CARLSON
}

\section{$\mathrm{T}$}

HE ADMINISTRATION recently presented its national economic plan for the eighteen-month period ending June 30, 1974. The Administration's plan is contained in three documents - the Federal Budget, the Economic Report of the President, and The Annual Report of the Council of Economic Advisers. ${ }^{A}$ Included in the economic plan is (1) a proposed program for the Federal budget, (2) goals for gross national product (GNP), output, prices, and employment, and (3) general recommendations for monetary actions by the Federal Reserve System.

The goals for the U.S. economy in the months ahead are stated most explicitly in the 1973 CEA Report. ${ }^{2}$ The goals include: a 10 percent advance in GNP from calendar 1972 to 1973 ( 9 percent from fourth quarter 1972 to fourth quarter 1973 ); a reduction in the annual rate of inflation, as measured by the consumer price index, to about 2.5 percent by the end of 1973 ; and a reduction of unemployment to about 4.5 percent of the labor force by the end of the year.

Proposed as consistent with the achievement of the 10 percent increase in GNP from 1972 to 1973 is a Federal budget program consisting of an expenditure increase (on a national income accounts basis) of 9.3 percent from calendar 1972 to 1973 , and an increase in the average tax rate because of previously legislated social security tax changes. Though the Administration is vague in its recommendation for monetary policy, the CEA does indicate that their target for GNP

is likely to require a slower increase of the supply of money and credit than was proper when the main objective was to encourage a guickened economic expansion in an environment of substantial unused resources."

This article summarizes and evaluates the Administration's economic plan. First, as background, last

1 The Budget of the United States Government, Fiscal Year Ending June 30,1974 (Government Printing Ofice, 1973), and Economic Report of the President, together with The Annual Report of the Council of Economic Advisers (Govermment Printing Office, 1973).

21973 CEA Report, chap. 3.

IIbid., p. 75 .

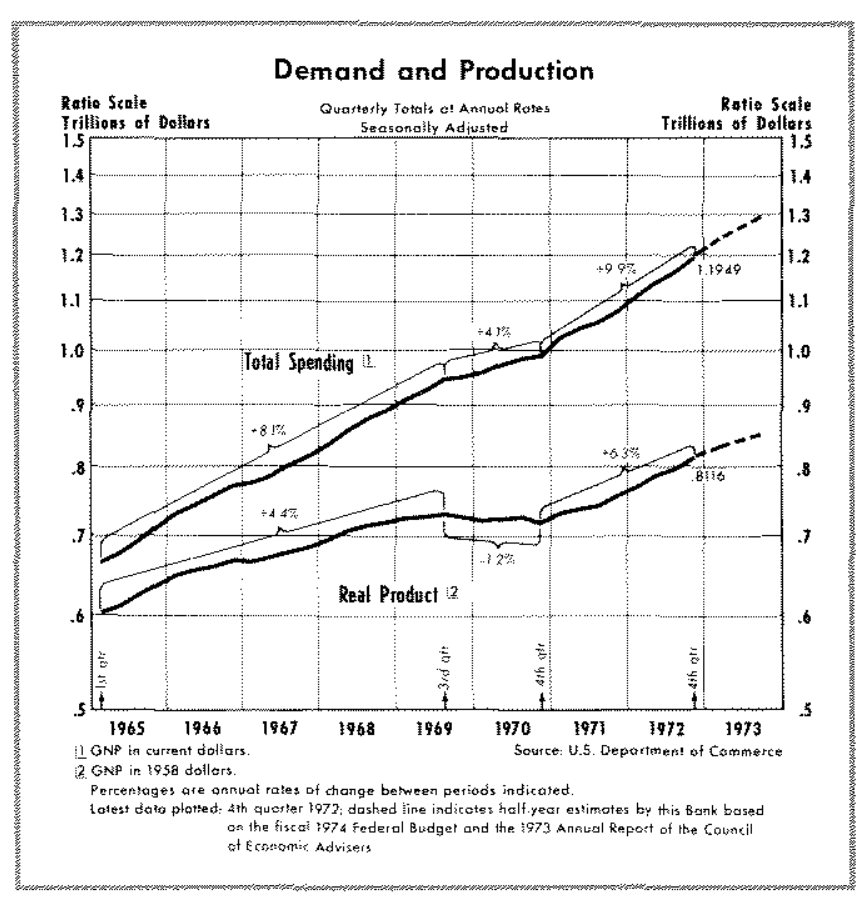

year's plan is compared with the record of achievement. Second, the proposed Federal budget program is presented in some detail, along with some discussion of monetary policy recommendations. Third, the economic plan is evaluated in terms of feasibility and internal consistency. To aid in this evaluation, alternative projections with the St. Louis model are presented as a basis for comparison.

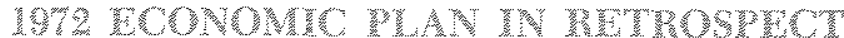

In early 1972 the U.S. economy was still in the process of adjusting to the major policy changes which were implemented on August 15, 1971. At that time, convertibility of the dollar into gold and other reserve assets was suspended, a surcharge was imposed on imports, the Federal excise tax was removed on automobiles, and a system of mandatory price-wage controls was introduced. Then in early 1972, the Administration took additional actions which reflected some doubts at that time about the strength of economic expansion. The Administration proposed a stimulative 
fiscal program to be accompanied by an accommodative monetary policy.

The following section summarizes the economic record for 1972 and compares that record with the Administration's goals. The record indicates that the Administration's overall goals came very close to being realized.

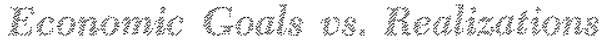

The CEA's Report of a year ago projected an increase in GNP of 9.4 percent from 1971 to 1972 . The realized increase was 9.7 percent. This error of 0.3 percent was the smallest for the CEA since 1964 and well below the average absolute error of 1.2 percent for CEA forecasts over the past eleven years.

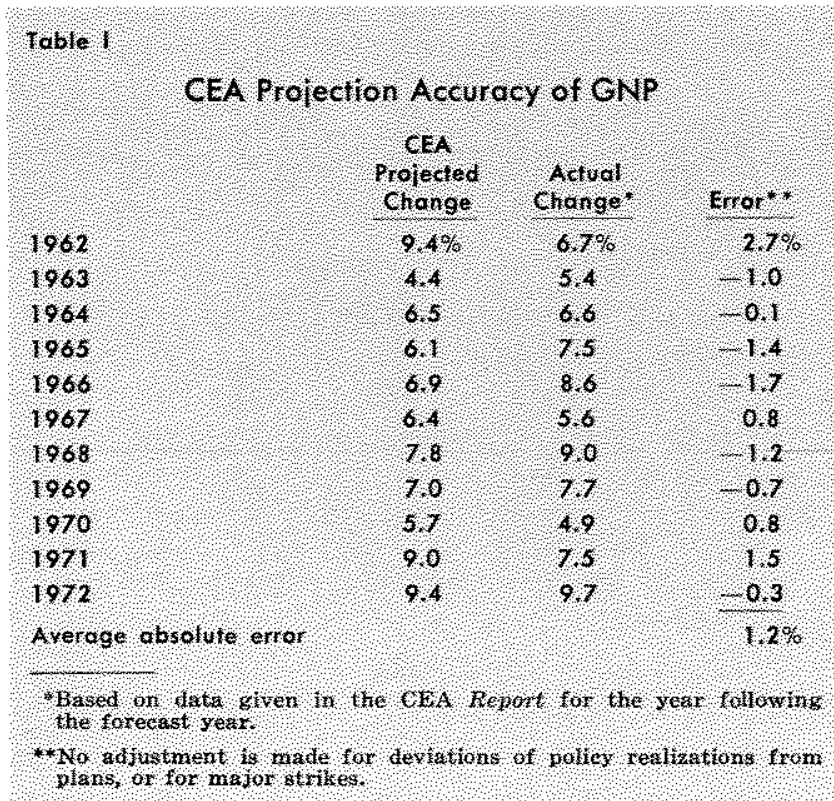

To further assess the accuracy of the Administration's 1972 projection for GNP, an analysis by components is presented in Table II. The CEA displayed uncanny accuracy on the GNP total, but, typically, this accuracy consisted of offsetting errors among the components. Estimates of the increases in personal consumption and Federal purchases were very accurate, but the increase in fixed investment - that is, business fixed investment plus residential construction was underestimated by about $\$ 11$ billion. This underestimate was largely offset by overestimates of inventory accumulation, state and local government purchases, and net exports. The error in projecting inventory accumulation may have been attributable, in part, to the underestimation of fixed investment. The overestimation of state and local purchases related to the timing of the revenue sharing program, but the

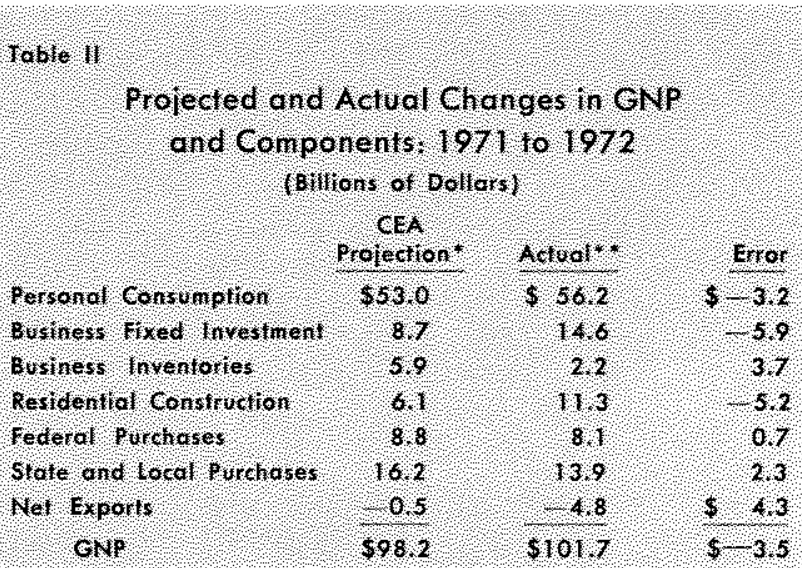

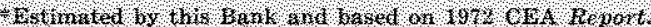

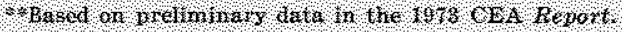

error in estimating net exports was simply a miscalculation of the impact of changes in international economic arrangements in late 1971.

The relatively accurate projection of total GNP carried through to projections of output, prices and unemployment (Table III). The CEA projected an increase of 5.9 percent in output, which actually grew at a more rapid 6.5 percent rate. Prices were projected to increase 3.2 percent; the actual increase was 3 percent. Unemployment was expected to average 5.6 percent in 1972 , declining from 6 percent in late 1971 to about 5 percent late in the year. The actual unemployment rate followed this projected pattern almost perfectly, and did in fact average 5.6 percent for the year.

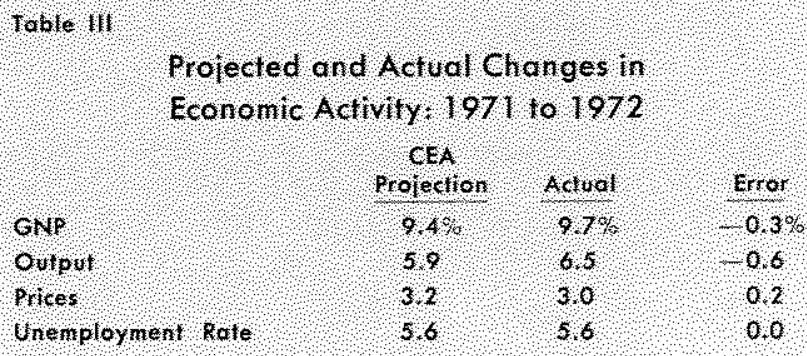

In summary, the CEA was very accurate in its prognosis of the course of the major economic atggregates for 1972. GNP, output, prices, and unemployment generally moved in accordance with the CEA targets. The projected change in total GNP was, for practical purposes, realized, but consisted of offsetting errors in the individual components of GNP.

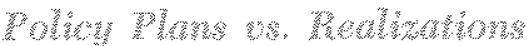

Assessment of the accuracy of any economic forecast depends on more than just a comparison of real- 
ized and projected values of GNP, output, and prices. A more complete evaluation also takes into account a comparison of policy plans with policy realizations. In other words, was the projection realized because of realized policy plans, or in spite of discrepancies between policy plans and realizations? This section compares the record of monetary-fiscal policy actions in 1972 with the original programs and recommendations.

Federal budget plans are compared with realizations in Table IV. Examination of NIA receipts and expenditures indicates that there was a substantial underestimate of receipts and a small overestimate of expenditures. The error in both of these estimates worked in the direction of making the realized deficit smaller than profected. Since receipts projections depend mainly on the forecast of GNP, it is surprising, given the accuracy of the GNP forecast, that the receipts estimate was so far off the mark. The reason, of course, was that the CEA did not forecast the extent of overwithholding of personal income taxes. Adjustment for this unexpected high flow of receipts indicates that the basic receipts estimate was much closer to realization, though still underestimated. U.S. Treasury estimates of the amount of overwithholding are in the neighborhood of $\$ 9$ billion, so the economic expansion and its greater-than-expected effect on receipts resulted in an error of about $\$ 4$ billion in the estimate of receipts.

On the expenditure side, the estimate was quite close, considering the magnitude of the increase which was planned. Furthermore, the error was attributable primarily to the delayed enactment of the revenue sharing program.

When the errors for receipts and expenditures are combined, they show that the NIA deficit was overestimated by almost $\$ 16$ billion. In general, these errors were of the type that suggest that the fiscal stimulus was not nearly as large as originally planned. However, examination of the NIA budget does not reveal the extent to which the budget was reflecting an underestimate of the strength of economic expansion.

To determine more accurately the extent of fiscal stimulus which occurred, the high-employment budget serves as a more appropriate, though still approximate, measure. By this measure, receipts were underestimated by only $\$ 4$ billion. This error indicates there

tChartes $A$. Waite and Joseph C. Wakefield, "Federal Fiscal Programs," Survey of Cutrent Business (February 1973), p. 20 .
Table $1 \mathrm{~V}$

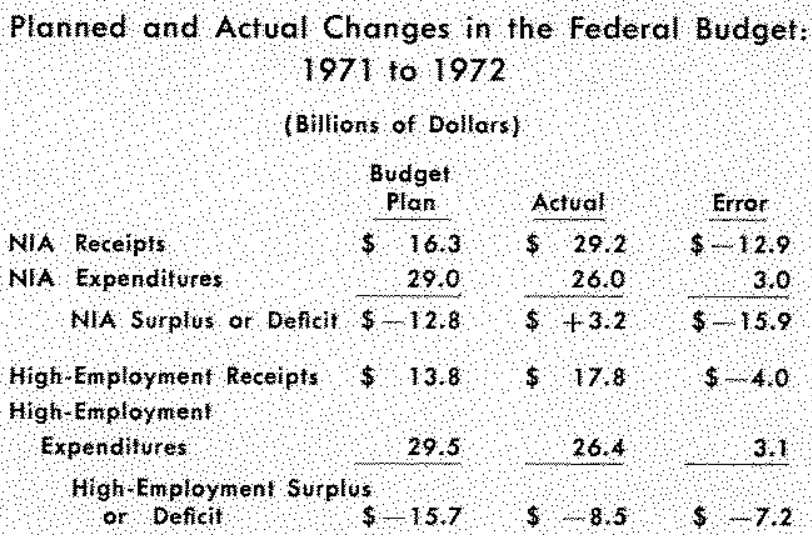

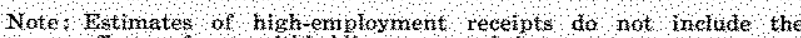
efrects of over witholding persond hidome taxes

was a miscalculation of the economic stimulus related to the Revenue Act of 1971 and the continuing effects of the Tax Reform Act of 1969. On the other hand, the estimate of high-employment expenditures was in error by about the same amount as for NIA expenditures.

As a result, examination of the change in the highemployment deficit indicates that the fiscal stimulus was about $\$ 7$ billion less than planned. Despite the stimulus being less than planned, GNP grew slightly faster than projected.

Consider now monetary actions as a part of the overall economic plan for 1972. The Administration did not indicate a specific growth rate for money; however, they did emphasize that monetary policy should be accommodative. Actual money growth was

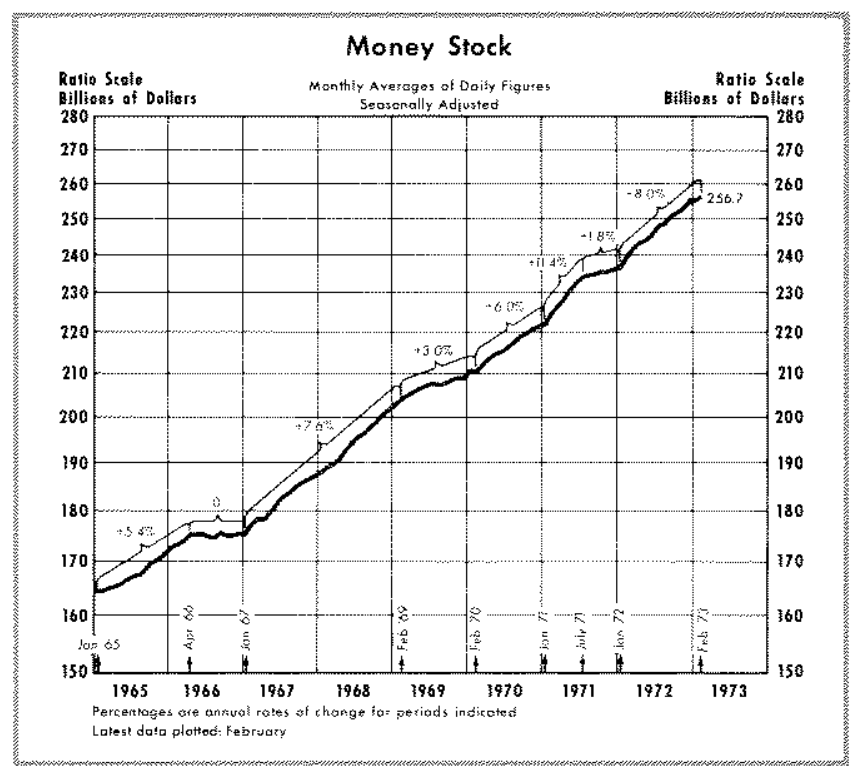

Page 4 


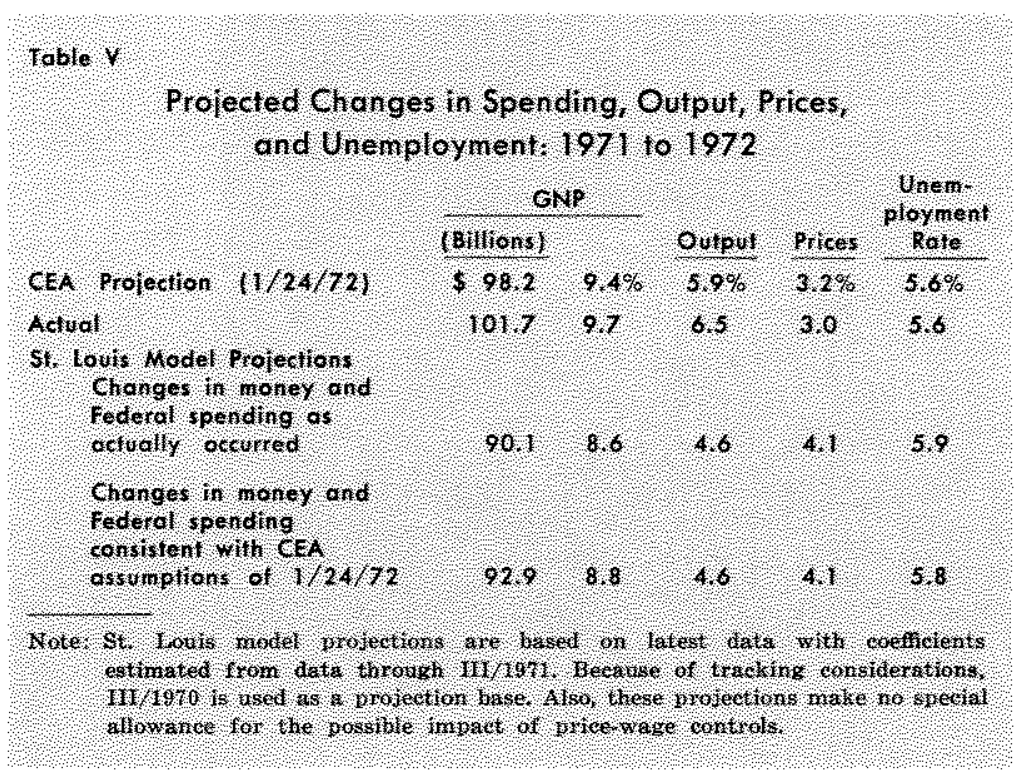

policy actions turned out to be less than if the initial policy recommendations had been realized. Nevertheless, it is clear that the St. Louis model underestimated the momentum of the economy in 1972, which, when viewed within the framework of the St. Louis model, translates into an underestimation of the growth in the income velocity of money.

\section{POLPU DILNS AND RECOMMENDATONS FOR 1973}

The Administration has projected a 10 percent increase in GNP for 1973. This GNP projection is offered as being consistent with about a 4.7 percent target for unemployment for the year ( 4.5 percent by year end) and a 3 percent rate of inflation for the year

7.4 percent from fourth quarter 1971 to fourth quarter 1972 , indicating that, relative to past experience, monetary actions were very expansive. The 1972 growth of money was faster than 92 percent of all previous years from 1947 to the present.

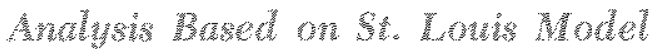

In general, the CEA projections proved to be very accurate, though the reasons why they were accurate are not clear. For purposes of comparison, some alternative simulations with the St. Lous model were conducted. Such simulations shed little direct light on the CEA projections, yet they provide a systematic basis for evaluating the 1972 economic experience.

Two projections of the St. Louis model are shown in Table V. The first projection uses money and highemployment expenditures as they occurred in 1972. The second projection is the result of using money and high-employment expenditures as recommended in the Administration's economic plan in January $1972 .{ }^{3}$ The first projection using actual movements of the two key policy variables indicates that, after the fact, the St. Louis model estimated the increase in GNP to be $\$ 90.1$ billion. The second projection indicates that movements of the policy variables in line with Administrative recommendations would have increased GNP by $\$ 92.9$ billion. Comparison of the projections indicates that the total impact of realized

\footnotetext{
${ }^{5}$ After the fact, a growth of money at a 7 percent rate was deemed consistent with the CEA forecast for 1972. This 7 percent rate was the average of two alternatives considered in an evaluation of the 1972 economic plan in this Review. See Keith M. Carlson, "The 1972 National Economic plan: An Experiment in Fiscal Activism," this Review (March 1972), pp. $3-10$.
} ( 2.5 percent by year end). These projections represent a continuation of the progress made in 1972 in reducing both unemployment and inflation.

Though the projections of the broad economic aggregates are very similar to actual experience in 1972 , there are some differences in the composition of GNP (Table VI). The most notable differences are with reference to business inventories, residential construction, net exports, and Federal purchases. Business inventory accumulation is projected to be much stronger in 1973 than in 1972 , while residential construction is expected to slow considerably compared to the very rapid 1972 advance. Net exports are projected to show a smaller deficit, though it should be noted that the CEA profections were released before the U.S. devalued the dollar on February 12. Federal purchases are projected to show little change in 1973, in contrast to the 8 percent increase in 1972 .

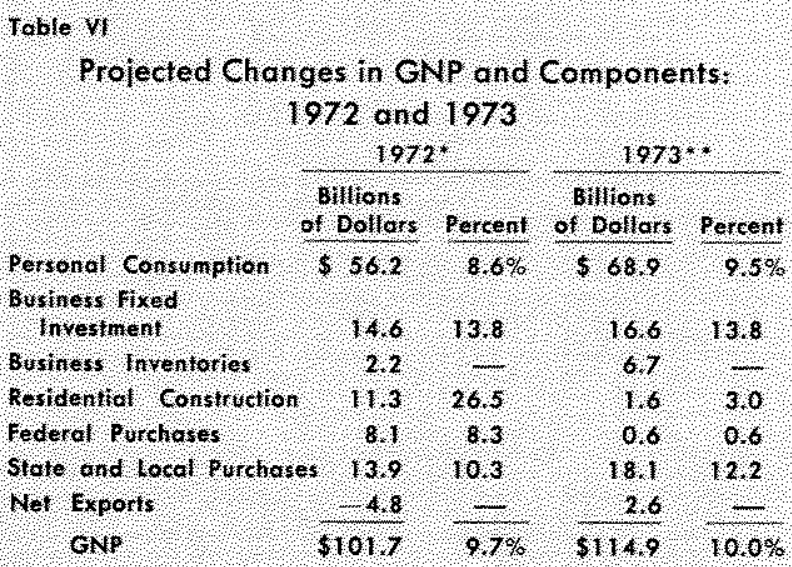

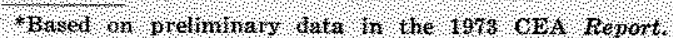

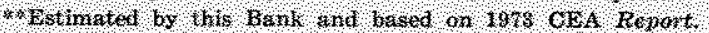




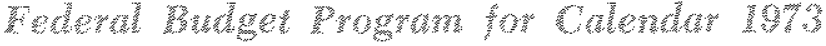

The budget plan for calendar 1973 calls for no further fiscal stimulus from calendar 1972. The highemployment budget, as estimated by this Bank, is projected to be in deficit by about $\$ 7$ billion in calendar 1973 , which compares with a $\$ 6$ billion deficit in 1972 and a $\$ 3$ billion surplus in 1971. The budget plan calls for a reduction in this deficit during the year, with an $\$ 11$ billion annual rate of deficit in the first half and a $\$ 4$ billion rate of deficit in the second half.

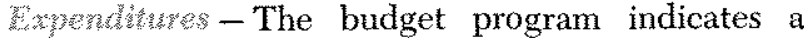
$\$ 23$ billion increase, or 9.3 percent, in Federal expenditures on an NIA basis for calendar 1973 (Table VII). This compares with an 11.8 percent advance in 1972 and a 6.8 percent average rate of increase from 1968 to 1971.

Defense spending is projected to decline in 1973 by 1.8 percent, compared to a 6.7 percent increase in 1972. However, defense spending is projected to advance 1.1 percent from the second half of 1972 to the second half of 1973. The effect of cessation of Vietnam hostilities has already occurred as defense spending declined at a 3 percent average annual rate from 1968 to 1971 , after increasing at a 16 percent average rate from 1965 to 1968 .

Nondefense spending, according to the Administration's budget, is projected to advance 14.2 percent in 1973, the same rate of increase as in 1972, and in line with the 13 percent average rate of increase from 1965 to 1971 . As with defense spending, year-to-year comparisons are misleading, because nondefense spending is projected to increase at a 2 percent annual rate from the first half 1973 to the second half of 1973. Nondefense spending in the first half of 1973 reflects the temporary effects of retroactive revenue sharing, the continuing effects of a permanent increase in social security benefits, and a $\$ 2.2$ billion pay increase for government employees.

zeconis - Federal receipts on an NIA basis are projected to rise by $\$ 19$ billion in 1973 , or by 8.4 per. cent. By comparison, receipts rose by 15 percent in 1972. These year-to-year comparisons are influenced in considerable measure by the effects of the overwithholding of personal income taxes in 1972.

To identify more precisely the basic trends for re. ceipts, the sources of change are shown in Table VXI. The only major tax change is the increase in the social security tax rate from 10.4 to 11.7 percent, effective January 1, 1973, and the expansion of the base for social security taxes from $\$ 9,000$ to $\$ 10,800$. The rise

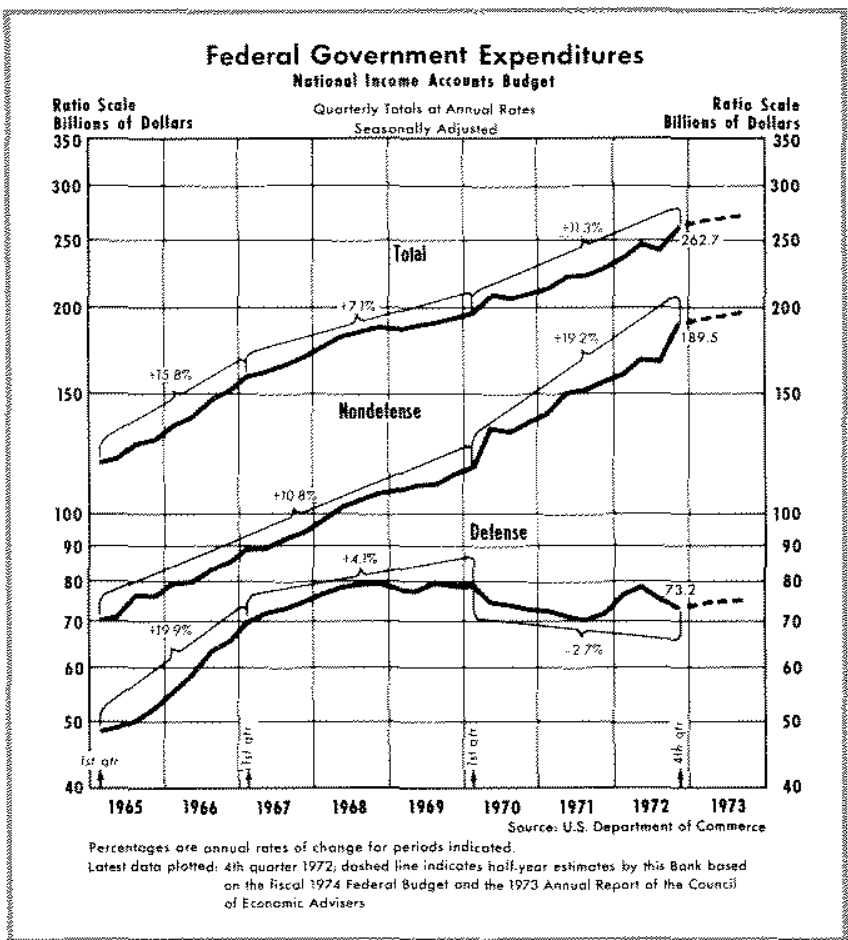

in receipts in 1973 is reduced relative to the increase in 1972 because of settlements attributable to overwithholding in 1972. In addition, receipts estimates for 1973 reflect the assumption that taxpayers will adjust downward their rate of withholding in 1973. After consideration of these tax changes, the estimate of the rise in receipts attributable to the advance of economic activity is about $\$ 25$ billion.

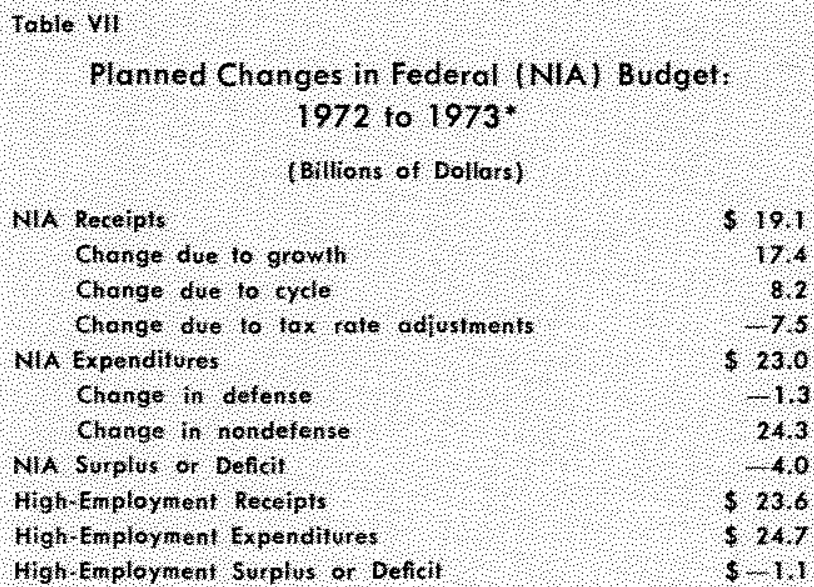

Fistinated by this Bank from the Federat Butget for fiscal 1974

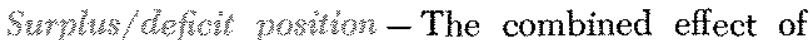
rising expenditures and receipts is a slight increase in the NIA deficit by $\$ 4$ billion, from $\$ 18.5$ billion in 1972 to $\$ 22.5$ billion in 1973 . However, since the NIA budget is influenced by the projected pace of eco- 
nomic activity, a more accurate indication of the economic impact of the budget can be obtained by examining the high-employment budget. Even on this basis, the estimate of the economic impact of the budget program is very approximate.

On a high-employment basis, the NIA budget is projected to be in deficit by $\$ 7$ billion in 1973. The plan of the Administration is to have the high-employment budget moving toward a surplus position by early 1974. This plan is predicated on the assumption that inflationary pressures will be developing in 1973 and a movement in the direction of fiscal restraint will be necessary to combat these pressures. This budget strategy stands in marked contrast to 1972 when a large fiscal stimulus was planned to accelerate economic expansion.

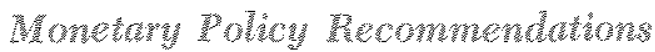

The Administration's overall economic plan is focused on the Federal budget, with very little mention of the role for monetary actions. The Economic Report of the President, for example, makes no mention of monetary policy. Furthermore, the 1973 CEA Report, in contrast to recent past reports, placed little emphasis on monetary actions, either with reference to their role in the 1972 expansion or in terms of recommendations for 1973. Monetary actions in 1972 were summarized simply as "accommodating" with respect to the financial requirements of last year's expansion.

The role for monetary policy in 1973 is summarized by the CEA as follows:

A gradial slowing of the expansion of money GNP to a steady rate consistent with the long-rus potential growth rate of the economy and reasonable price stability is also an appropriate goal for monetary policy. This is likely to require a slower increase of the supply of money and credit. . .6

\section{IVA WONONCO ML AN}

The Administration's projection for 1973 is very close to the consensus of other forecasts. For purposes of comparison, the CEA projections are evaluated with reference to the St. Louis model. This section focuses on two considerations: (1) Is the projected increase in total spending consistent with the proposed set of stabilization policies, and (2) are the price and unemployment goals consistent with the projected increase in total spending?

41973 CEA Report, p. 75.

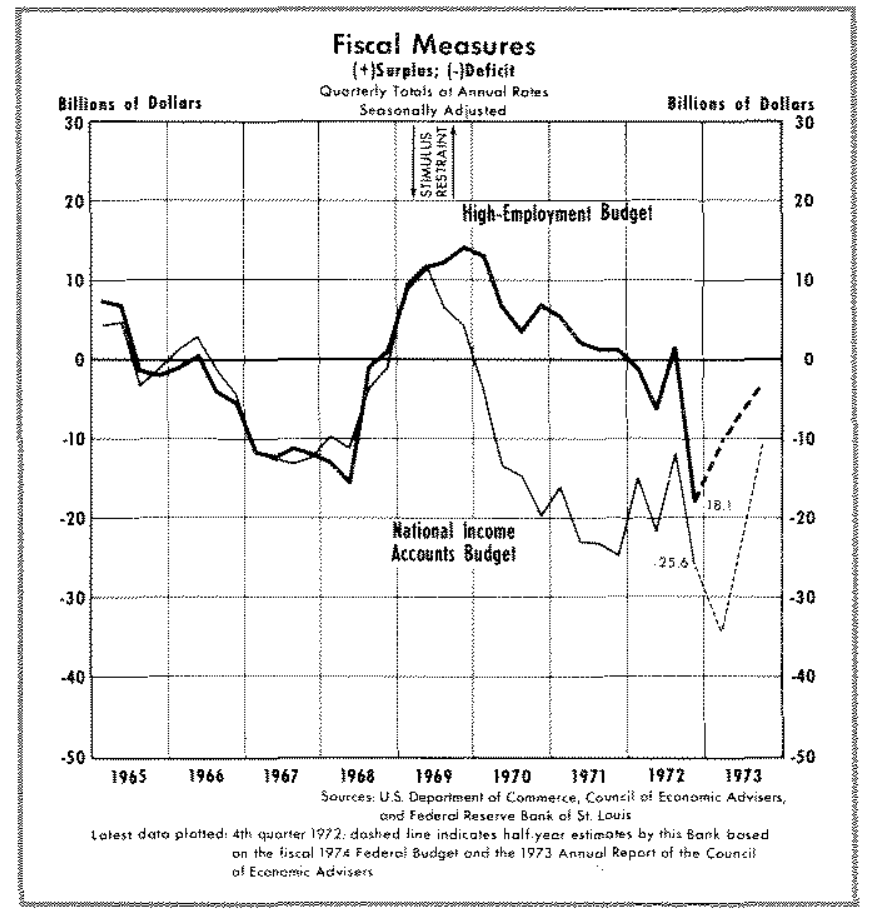

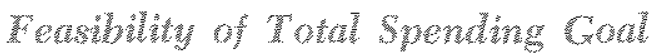

To determine the feasibility of the Administration's projection of a $\$ 115$ billion, or 10 percent, increase in CNP, two combinations of policies were conducted with the St. Louis model. These combinations of policies are:

(1) increases of Federal spending as proposed in the budget and an expansion of money at a steady 6 percent anmul rate from fourth quarter $1972 ;$

(2) increases of Federal spending as proposed in the budget and an expansion of money at a steady 8 percent annual rate from fouth quarter 1972.

The two alternatives for money growth represent two illustrative courses of monetary action. It should be emphasized that they are illustrative and in no way directly attributable to the CEA or the Federal Reserve System. The steady 6 percent path of money growth is presented as being consistent with the recommendation of the CEA, at least in direction if not

\footnotetext{
TThe assumed path for Federal spending rellects special considerations which are necessary to assess the economic impact of fiscal actions within the framework of the St. Loujs model. The impact of fiscal actions on GNP in the St. Louis model works only through a direct effect on GNP. As a result, large variations in Federal expenditures end to intronuce distortions in the results because the sample pertod used for estimation of the coefficients is relatively free of such variations. And even to the extent such variations are vislent in past experience, the process of estimating regression coeffcients is itself an averaging process. More specifically, the rise in experaditures in the fourth cuarter of 1972 was attributable in large meastre to retroactive revenue sharing. Information relating to the special nature of this expenditure increase was used to introduce a judgmental element into the model inputs so as to reduce distortions in the outputs of the model.
} 


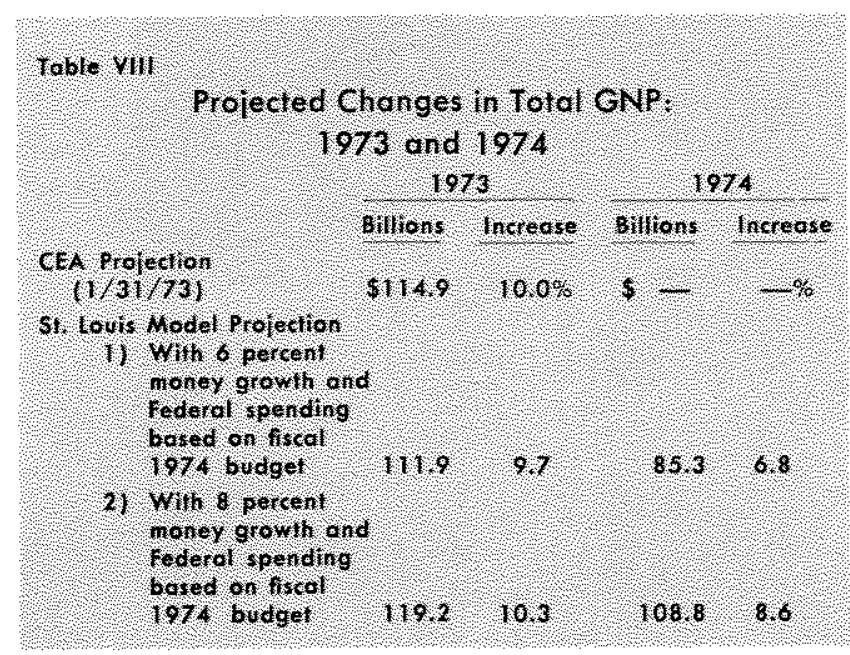

in precise magnitude. The steady 8 percent money path would represent an approximate continuation of the course of monetary actions in 1972 .

The results for these combinations of policies are shown in Table VIII. The combination of a steady 6 percent growth of money and government spending based on the fiscal 1974 budget yields results which are roughly consistent with the CEA projections. The conclusion is offered here that the CEA projection is indeed feasible if the impact of retroactive revenue sharing is distributed more evenly over time than the NIA expenditure estimates would indicate.

The case with steady 8 percent money growth is shown for illustration. If money should grow at a rapid 8 percent rate, the $S$. Louis model indicates that GNP would increase by about $\$ 5$ billion more than the CEA forecasts. Furthermore, it should be remembered that the St. Louis model contains an implicit assumption that velocity will grow at a relatively slow rate in the range of 2.2 to 2.8 percent from 1972 to 1973 .

In summary, the CEA projection appears to be feasible and realistic. There is a definite possibility, however, that the expansion of nominal GNP will be stronger than planned if (1) money grows faster than at a 6 percent rate, (2) velocity increases more rapidly, or (3) some combination of the two.

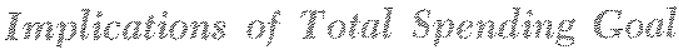

Aside from the possibility of attaining the GNP goal, attention is now focused on the Administration's price and unemployment goals. Table IX, on the following page, shows the implied paths of output, prices and unemployment as given by the St. Louis model using an estimated path for GNP consistent with the CEA forecast. There are two St. Louis model projec-

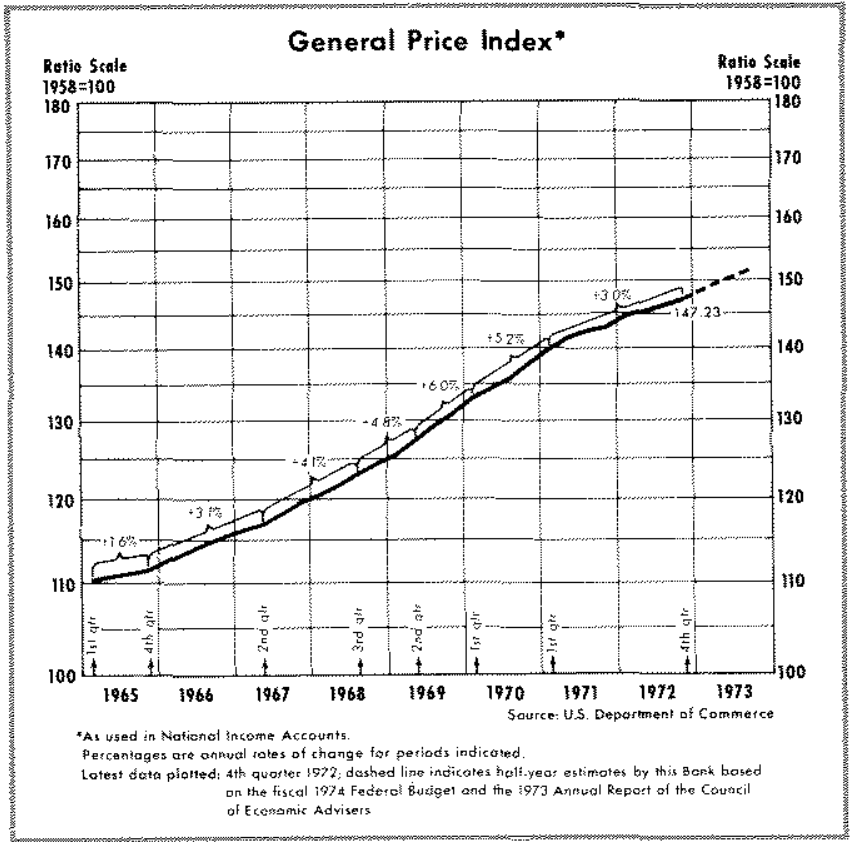

tions which reflect different assumptions about the longer-run effects of the price-wage control program.

Examination of the table indicates the critical importance of the assumption about the success of Phase III of the price-wage control program, as well as the lasting effects of the earlier phases of the program. The two alternatives reflect assumptions about these lasting effects. The first St. Louis model projection assumes that past controls were effective in permanently reducing the price level from what it otherwise would have been, and that the 1973 price-unemployment mix will be determined within that context. The other altemative assumes that price-wage controls were not effective in permanently reducing the price level, and prices will thus show a catch-up effect toward the basic trend as determined by monetaryfiscal actions during the period of controls.

Examination of these alternatives indicates that the Administration's forecast is roughly consistent with the "effectiveness of controls" version of the St. Louis model. With this version of the model, prices are projected to rise 3.3 percent in 1973 , only slightly higher than that projected by the CEA. Unemployment is projected to average 4.7 percent, about the same as the Administration's projection.

Consider now the "ineffectiveness of controls" version of the St. Louis model. This model shows a rapid run-up in prices in 1973, which illustrates the assumption that prices will reflect a level consistent with the longer-run path of monetary growth. In other words, the assumption underlying this version of the model is that it is not possible to control prices by fiat over the 


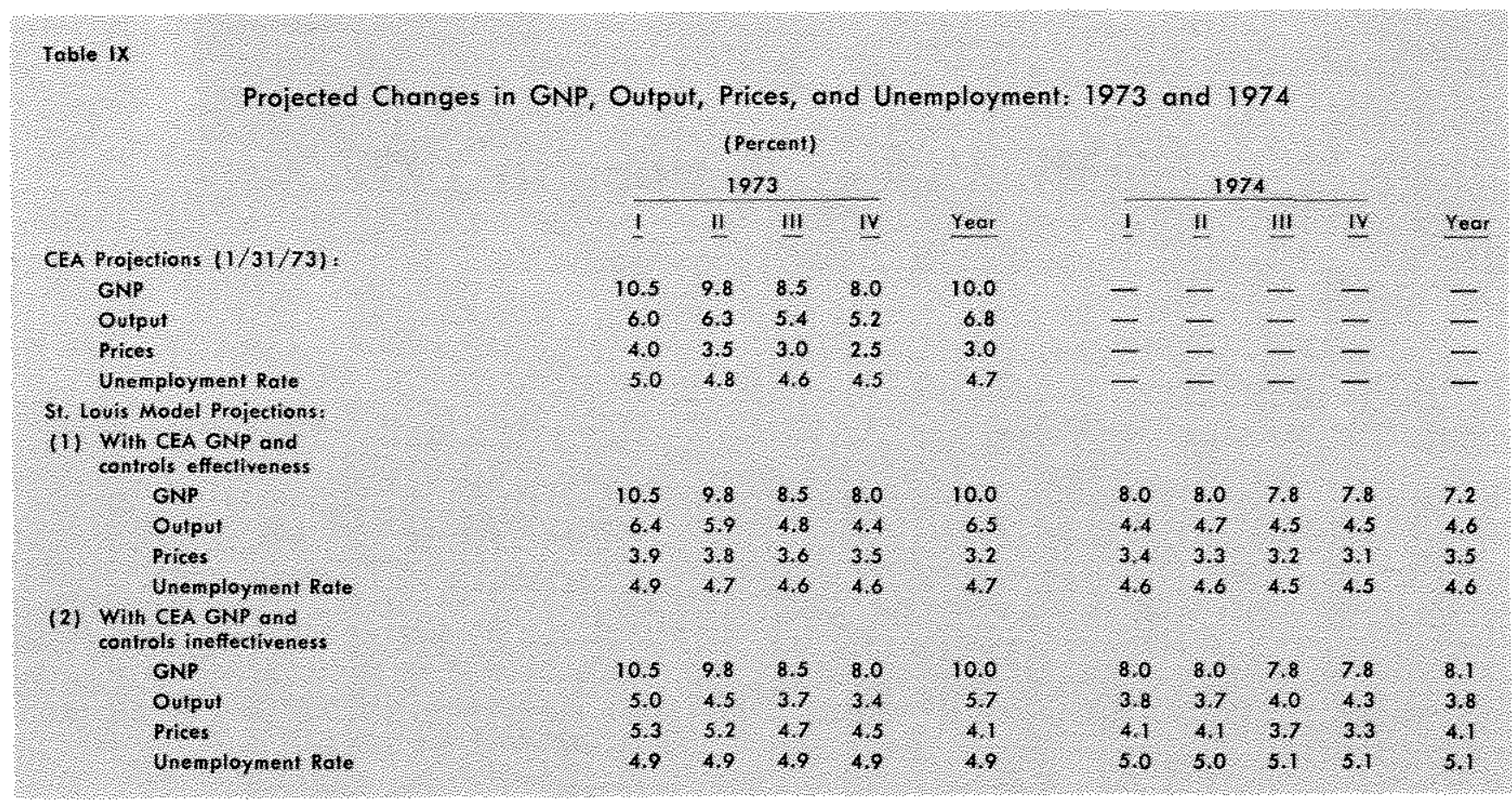

longer run. This particular version of the model assumes that this catch-up process will take two years, though this is an arbitrary assumption. Given this version of the model and its assumptions, the outlook for employment is somewhat less optimistic, showing an average unemployment rate of 4.9 percent for 1973 .

Any conclusions about the attainability of the Administration's price-unemployment goals are very tentative. In particular, it still remains to be determined whether the price-wage control program has had any lasting effects on price trends. Aside from such shortrun considerations, it is perhaps more certain that monetary-fiscal actions over the next two years are crucial in the determination of price trends beyond 1974. An awareness of these longer-run considerations is demonstrated in the CEA Report, however, when they suggest the urgency of getting the economy on a noninflationary growth path.

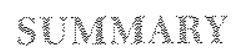

The Administration has projected another year of rapid growth in GNP. Accompanying this rapid growth is a belief that unemployment will be reduced further and inflation will continue to slow. Over the longer run the CEA has made it clear that it seeks the objective of slowing the pace of economic advance so as to be consistent with noninflationary growth.

To achieve their objectives, the Administration proposes a Federal budget program that maintains a stimulative posture in 1973 , but with the degree of stimulus moderating during the year. At the same time, the Administration recommends a slowing in monetary growth from the rapid 7.4 percent advance in 1972 ,

Using the St. Louis model as an aid in evaluating the 1973 economic plan, it was found that the total spending goal was feasible. This goal for total spending leaves little margin for error, however, for any one or a combination of several eventualities could push GNP above the Administration's goals. The GNP goal requires that money growth does not exceed 6 percent, that Federal spending rises in line with projections, and that the income velocity of money increases at a rate of about 3 percent. To the extent that the income velocity of money rises at a more rapid rate, the growth of the money stock would have to be correspondingly slower.

Assessment of the Administration's goals for prices and unemployment is much more difficult. Due to the uncertainty that still exists as to the lasting effects of the price-wage control program, as it has been administered up to this time, achievement of these goals is much more tenuous. A version of the St. Louis model, which builds in the assumption of past success of price-wage controls, indicates that the Administration's price-unemployment goals are attainable in 1973, given their assumptions about monetary-fiscal. actions. But any tendency towards a catching-up of prices will delay the attainment of either the price or the unemployment goal. 